\title{
Climate change adaptation frameworks: an evaluation of plans for coastal Suffolk, UK
}

\author{
J. Armstrong ${ }^{1}$, R. Wilby ${ }^{1}$, and R. J. Nicholls ${ }^{2}$ \\ ${ }^{1}$ Geography Department, Loughborough University, Loughborough, UK \\ ${ }^{2}$ Civil Engineering \& the Environment, University of Southampton, Southampton, UK
}

Correspondence to: J. Armstrong (j.armstrong@lboro.ac.uk)

Received: 28 February 2015 - Published in Nat. Hazards Earth Syst. Sci. Discuss.: 22 June 2015

Revised: 7 September 2015 - Accepted: 5 October 2015 - Published: 18 November 2015

\begin{abstract}
This paper asserts that three principal frameworks for climate change adaptation can be recognised in the literature: scenario-led (SL), vulnerability-led (VL) and decisioncentric (DC) frameworks. A criterion is developed to differentiate these frameworks in recent adaptation projects. The criterion features six key hallmarks as follows: (1) use of climate model information; (2) analysis of metrics/units; (3) socio-economic knowledge; (4) stakeholder engagement; (5) adaptation of implementation mechanisms; (6) tier of adaptation implementation. The paper then tests the validity of this approach using adaptation projects on the Suffolk coast, UK. Fourteen adaptation plans were identified in an online survey. They were analysed in relation to the hallmarks outlined above and assigned to an adaptation framework.

The results show that while some adaptation plans are primarily SL, VL or DC, the majority are hybrid, showing a mixture of DC/VL and DC/SL characteristics. Interestingly, the SL/VL combination is not observed, perhaps because the DC framework is intermediate and attempts to overcome weaknesses of both SL and VL approaches. The majority $(57 \%)$ of adaptation projects generated a risk assessment or advice notes. Further development of this type of framework analysis would allow better guidance on approaches for organisations when implementing climate change adaptation initiatives, and other similar proactive long-term planning.
\end{abstract}

\section{Introduction}

There is increasing agreement between scientific and political spheres of society that the potential impacts of anthropogenic climate change need addressing via both mitigation and adaptation as a twin-tracked approach (Dang et al., 2003; Kleina et al., 2005; Pielke Jr., 2009). The Intergovernmental Panel on Climate Change (IPCC) Fifth Assessment Report (AR5) states that there are significant co-benefits, synergies and trade-offs between mitigation and adaptation efforts. However, tools to understand and manage these interactions remain limited (IPCC, 2013). The necessity of adopting the twin-tracked approach is increasingly being acknowledged across a range of sectors (Craig, 2010; Delgado et al., 2011; Semenza et al., 2011; Wong et al., 2014) and is particularly appropriate for regions already experiencing stress from impacts of climate variability and change (Solomon et al., 2008). However, there is growing concern that examples of theoretical best practice for implementing adaptation, within the academic literature, may not translate efficiently to facilitate, deploy and monitor real-world adaptation actions (Eisenack and Stecker, 2012).

It is important to note that the process of climate change adaptation is not a new phenomenon. Human activity along with the autonomous behaviour of flora and fauna have always adapted to the natural variability in the long-term climate. Burton et al. (2004) assert that the innovative aspect is in fact incorporating future climate risk into policy making therefore making adaptation mandatory. They affirm that although our understanding of climate change and its potential impacts has become clearer, the availability of practical guidance on implementing adaptation has not kept pace. 
UNEP (2014) highlighted this by stating that adaptation finance will need to increase by $438 \%$ by 2050 to ensure that developing nations are resilient to the potential impacts of climate change. This highlights the global need for adequate and accurate guidance to avoid maladaptation.

The expansion of the UK's nuclear-power-generating capacity is an example of a twin-tracked approach to avoid dangerous climate change. Expanding nuclear capacity has been pitched as an effective way of mitigating $\mathrm{CO}_{2}$ emissions, thereby contributing to carbon reduction targets set out in Her Majesty's Government Climate Change Act (2008). Provided that concerns about site safety and radioactive waste transport and disposal can be adequately addressed, nuclear power could replace baseload fossil fuel electricity generation in many parts of the world (Sims et al., 2003). This said, the vulnerable coastal locations in which UK nuclear power stations must be developed (due to cooling requirements) will require extensive long-term (100+ years) adaptation efforts, from multiple stakeholders in the coastal zone, in order to bolster against potentially detrimental impacts of climate change. All coastal sites are vulnerable to the possible impacts of climate change, namely sea-level rise and increased storminess, both projected to enhance coastal cliff erosion and coastal retreat (Hackney at al., 2013). Therefore, it is vital that appropriate adaptation guidance is provided, especially regarding long-lived national infrastructure in the coastal zone.

The neighbourhood surrounding the nuclear power station at Sizewell, on the Suffolk coastline, UK, provides a useful case study where long-term adaptation is essential. The Suffolk coastline features both Sizewell A (decommissioned) and Sizewell B (operational) nuclear power stations with one of the sites of the proposed nuclear new builds; Sizewell C. The "nuclear neighbourhood", in this instance, is defined as a $20 \mathrm{~km}$ buffer around the nuclear development which reflects the radius in which the nuclear new build developers, EDF Energy, will need to address ecological impacts.

This paper will analyse to what degree theoretical climate change adaptation frameworks are applicable in practice, using coastal Suffolk as a case study. The paper develops a criterion which outlines six hallmarks describing the characteristics of each theoretical adaptation framework: scenarioled (SL), vulnerability-led (VL) and decision-centric (DC). This criterion is used as a tool to classify each adaptation project.

The paper is structured as follows. First, three theoretical adaptation frameworks established in the literature will be outlined, worked examples presented as well as strengths and weaknesses of each framework highlighted. Next, a criterion for identifying each framework is presented (Table A1). The case study area is introduced before outlining the methodology used in order to determine the validity of the theoretical adaptation frameworks into everyday practice. The results section establishes to what extent SL, VL and DC frameworks are utilised by stakeholders in the study area. The dis- cussion then explores possible reasons for discrepancies between theoretical adaptation frameworks and adaptation in practice. The conclusion sets out the headline findings and identifies opportunities for further research.

\section{Theoretical context of climate change adaptation frameworks}

There are multiple definitions of adaptation (Smit and Wandel, 2006). With reference to climate change, adaptation can be defined as "adjustments in ecological-socio-economic systems in response to actual or expected climatic stimuli, their effects or impacts" (Pielke, 1998, p. 161). In addition, adaptation refers to the "adjustments in individual groups and institutional behaviour in order to reduce society's vulnerability to climate" (Fankhauser et al., 1999, p. 74). Adaptation is not a new phenomenon; there are currently a multitude of adaptation schemes operating on a range of scales and sectors within society and addressing a wide range of risks including climate extremes and variability. These adaptation initiatives occur from the international level to community-based partnerships.

A range of frameworks designed to aid climate change adaptation exist within the literature. Existing frameworks predominantly define adaptation in different contexts and propose tools that may be used to aid climate change adaptation. For example, current frameworks outline barriers to adaptation (Moser and Ekstrom, 2010; Measham et al., 2011) or attempt to establish what makes climate change adaptation "successful" (Adger et al., 2005) and define key terminology used in the assessment and implementation of adaptation initiatives (Füssel, 2007). These frameworks are often sectorspecific and are bounded by situational variables such as regional demographics, resource availability and politics.

In order to provide the needed practical guidance on implementing adaptation initiatives, a thorough understanding of the nature of current adaptation efforts must first be established. A review of the climate change adaptation literature demonstrates that when implementing adaptation initiatives, there are three distinct framework approaches that stakeholders may utilise: SL, VL and DC. This review was not sectorally or regionally specific. The following subsections outline the nature of these three adaptation frameworks and key literature from the review which form the basis of the identification criterion presented in Sect. 3.

\subsection{Scenario-led adaptation frameworks}

These frameworks apply conventional methods of regional climate downscaling from climate model projections under a range of greenhouse gas emissions scenarios. Downscaled scenarios are then fed into impact models to examine how changes in climate might affect a given region and impact metric(s) such as crop yield, streamflow or coastal retreat 
(Hackney et al., 2013). Only then are adaptation options considered and implemented. Wilby and Dessai (2010) highlight that although the SL framework is the approach most widely used by the scientific community (to date) there are few examples of actual adaptation decisions arising from this route. They contend that the vast majority of research stops at the impact assessment stage. The most likely reason is that SL approaches are plagued with limitations surrounding uncertainty, largely due to the technical ability of the models themselves (Wilby et al., 2002). Although the ability to model the response of coastal systems to the potential impacts of climate change is advancing (Hackney et al., 2013), the range of uncertainty expands with each step of the adaptation process (Wilby and Dessai, 2010). This means that decisions governing adaptation responses must contend with a wide range of uncertain futures (Fig. 1). Uncertainty proceeds from different socio-economic and demographic pathways, their translation into concentrations of atmospheric greenhouse gas (GHG) concentrations, expressed climate outcomes in global and regional models, translation into local impacts on human and natural systems, and implied adaptation responses (Wilby and Dessai, 2010).

The limitations of the SL approach have been recognised for some time. Dessai et al. (2004) assert that whilst climate modelling remains uncertain, the role played by modelling in adaptation planning depends largely on the adaptation assessment approach and the technical and economic feasibility of handling probabilistic outputs from climate models.

\subsection{Vulnerability-led adaptation frameworks}

Vulnerability-led frameworks seek to identify and reduce vulnerability to past and present climate variability. VL frameworks recognise that complex socio-ecological demographics are factors that must be considered when implementing appropriate and effective adaptation to the potential effects of climate change. As such, the focus of this framework is on identifying factors and controls that govern communities' ability to successfully cope with climate-related threats, commonly involving a community risk assessment (Van Aalst et al., 2008). Adaptation occurs in the form of improving coping strategies or by reducing exposure to known threats.

However, lengthy observations are needed to assess magnitudes and frequencies of extreme events as well as their associated societal and environmental consequences. In practice, climate vulnerability is determined by multiple factors such as economic status, social equity, food security, education, access to natural resources and technology, physical and institutional infrastructure (Brooks et al., 2005). The profiles of these vulnerability variables are context-specific, meaning that one assessment cannot be readily transferred to other regions due to variations in socio-economic and cultural factors (Van Aalst et al., 2008).

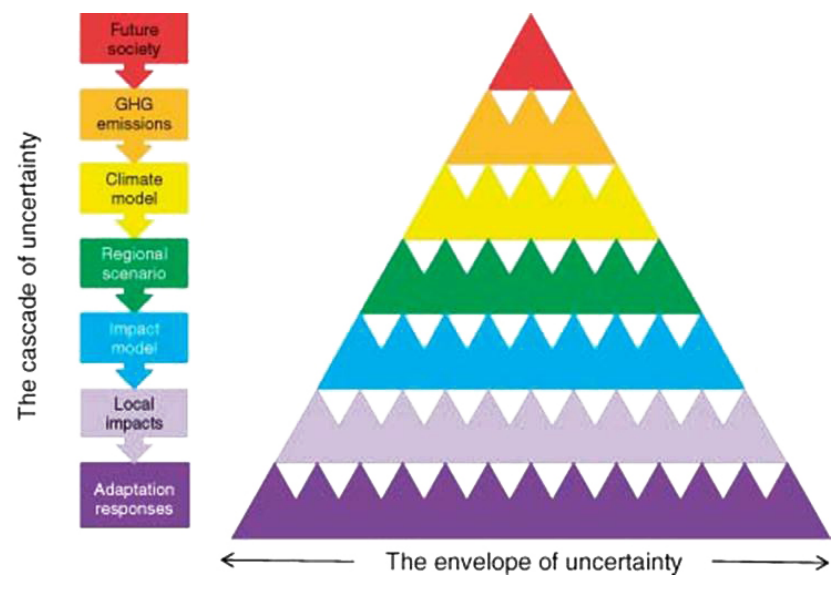

Figure 1. Cascade of uncertainty; the increasing numbers of triangles at each level symbolise the growing number of permutations and hence expanding envelope of uncertainty. Source: Wilby and Dessai (2010).

In addition, Wilby and Dessai (2010) highlight that in many parts of the world, climate variability is already stressing human and environmental systems. For example, parts of North Africa and the Middle East are already facing a water crisis due to demographic and economic pressures. Consideration of complex socio-economic structures is not only necessary at the risk assessment stage but also when thinking about socio-economic development pathways over long-term horizons. O'Neill et al. (2014) highlight this and propose the use of conceptual frameworks using Shared Socio-economic Pathways (SSPs). They define SSPs as reference pathways used for plausible alternative trends in the evolution of society and ecosystems over a century timescale in the absence of climate change and climate policies.

\subsection{Decision-centric adaptation frameworks}

These adaptation frameworks are situated between SL and VL approaches (Brown et al., 2012). DC or stress-testing frameworks attempt to overcome the irreducible uncertainty associated with climate change projections by focusing attention on identifying vulnerabilities/coping capacities and managing risks through robust, low-regret adaptation methods.

This climate risk management approach begins with the identification of the vulnerabilities in a given neighbourhood by asking stakeholders and appropriate experts the degree to which the given area could cope with changes in boundary conditions and establish what levels of climate change would require substantial infrastructure investment and/or policy shifts. The identified vulnerabilities and thresholds are then formalised into a model that relates changes in the physical climatic conditions to the performance of these metrics corresponding to vulnerabilities (Brown et al., 2012). The importance of the identification of critical thresholds that may 
affect the resilience of a system is an aspect of the adaptation process that is currently being given more credence in the face of uncertainty (Brown and Wilby, 2012).

One advantage of the DC framework is that it may be updated immediately if conditions governing risk change. The framework is also useful when trying to determine which uncertainties are most important from the viewpoint of the decision maker as individual metrics can be stress-tested. One pioneering case study, in which a DC approach was successfully utilised, was the International Upper Great Lakes Study (IUGLS), which established rules for regulating water levels in the Great Lakes.

Defining control rules for the Great Lakes was problematic due to significant levels of natural variability along with poorly understood lake dynamics. This means that potential climate impacts on hydroelectric power, navigation and ecosystems are difficult to predict. As a result of this uncertainty, an optimal plan based on identifying the most probable future scenario was rejected. Instead, a plan was devised in three main phases: (1) stakeholder groups identified key vulnerabilities and defined acceptable and unacceptable lake levels for each impact area; (2) a dynamic regulation plan was developed that is responsive to a wide range of climate conditions; and (3) an adaptive management process was established for reviewing the performance and updating the dynamic regulation plan (Brown et al., 2012).

The DC approach encompasses climatic change projections, potential impacts and community responses as an interlinked system; as such this framework is inherently multidisciplinary, often involving multiple stakeholder groups. This complex approach therefore requires engagement and promotes interdisciplinary learning between cross-sectorial participants. The DC framework approach demonstrates that when faced by uncertain climate change, all parties must be flexible in the execution of the adaptation plan.

\subsection{Evaluating climate change adaptation frameworks}

Given the prospect of unavoidable climate change it is vital that effective decision frameworks are used to guide the implementation of appropriate adaptation of the coastal zone surrounding critical national infrastructure. There have been calls to re-examine ways in which climate risk information is used in adaptation and development planning (Wilby and Dessai, 2010). The presented criterion (Sect. 3) builds on work by Ekström et al. (2013), who used a matrix approach to deconstruct and analyse different frameworks, including their approach to climate risk assessment, treatment of uncertainty and underlying sources of evidence.

\section{Climate change adaptation framework identification criterion}

The literature suggests that climate change adaptation efforts typically adopt one of the three theoretical framework approaches described in Sect. 2. Table A1 presents a criterion that may be used to identify which framework an organisation may be implementing. Six key hallmarks are present in all adaptation initiatives: (1) use of climate model information; (2) analysis of metrics/units; (3) socio-economic knowledge; (4) stakeholder engagement; (5) adaptation of implementation mechanisms; (6) tier of adaptation implementation. The nature of the hallmark depends on the framework approach adopted to implement climate change adaptation.

The remainder of this paper tests the applicability of the criterion using the coastal zone of Suffolk as a test case. This region is chosen because of the long history of autonomous and planned adaptations, together with proposed developments of long-lived infrastructure that must be resistant to climate change even beyond the 21 st century (Wilby et al., 2011).

\section{The Suffolk coastline}

The Suffolk coast recession rates of "soft rock" cliffs are amongst the highest recorded in the UK and even globally (French, 2001). In the UK the projected impacts of climate change are estimated to cause approximately GBP 126 million of economic loss per year from coastal erosion alone (Dickson et al., 2007). The Department for Environment, Food and Rural Affairs (DEFRA, 2012) estimate that $54 \%$ of the Suffolk coast is currently retreating with erosion rates varying from $0.4 \mathrm{~m}$ a year to $2 \mathrm{~m}$ a year.

Many organisations in the vicinity of Sizewell are vulnerable to the potential impacts of coastal change. However, these stakeholders may have different interests and points of concern. This is coupled with the extensive historical modifications the Suffolk coastline has experienced though coastal management. For example many current coastal defences in Suffolk are a reaction to the major 1953 storm surge, while shoreline management planning is a more recent national adaptation process which is taking a more strategic approach to managing erosion and flood risks (Nicholls et al., 2013). Conflicting interests and priorities create a challenging environment in which to negotiate and approve the best way to deploy adaptation projects to tackle climate change. Stakeholders have strong vested interests in coastal management decisions and this will continue into the future. The presence of a nuclear power station may affect the management strategy of the adjacent coastline when looking into the future.

The most significant threats posed by climate change to UK coastal zones are by sea-level rise and possible increased wave attack, storminess and storm surges, which all have relevance to the Suffolk coastline. Potential impacts to the study 


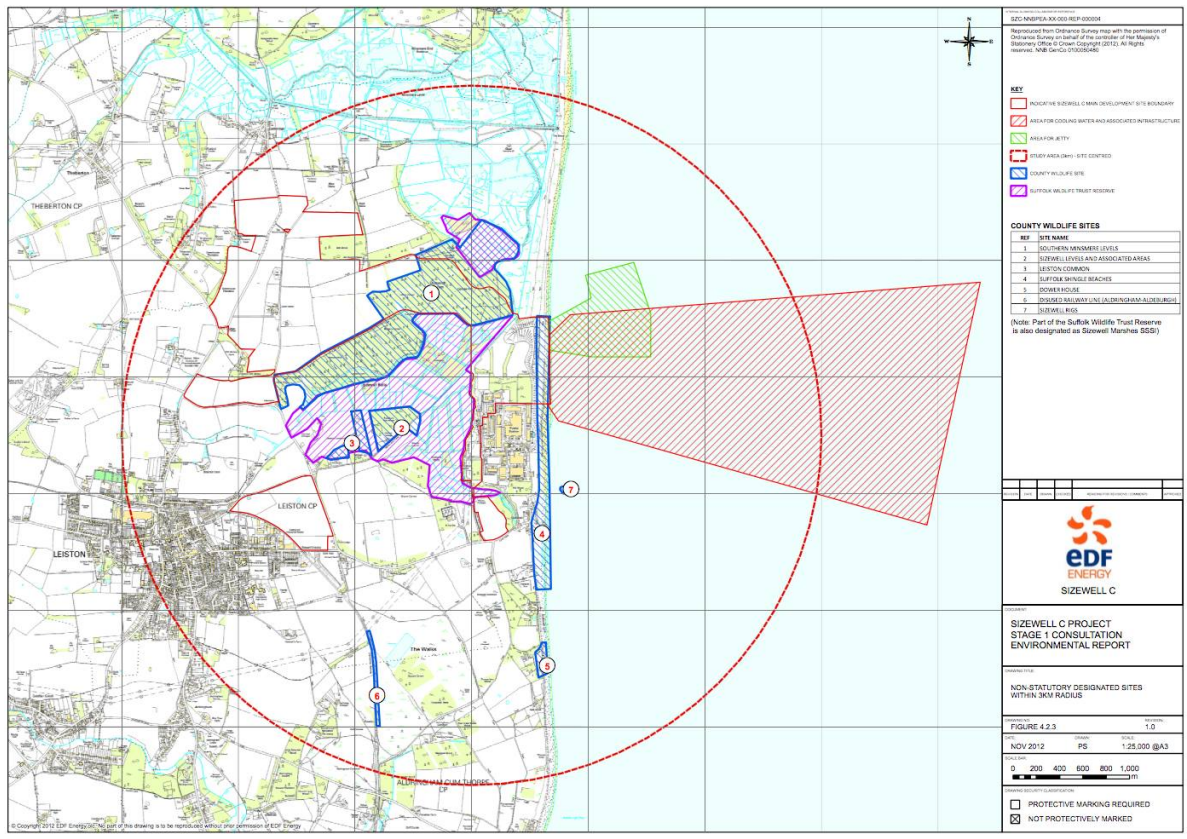

Figure 2. Suffolk coastline featuring nuclear Sizewell nuclear power stations and Minsmere RSPB reserve. Nuclear neighbourhood represented by EDF $20 \mathrm{~km}$ environmental impacts buffer. Source: EDF Energy (2012), Stage 1 Consultation documents.

site include increased erosion and flooding, and more locally saline intrusion. These may significantly modify both biotic and abiotic environments and could cause geomorphological and ecological change in the Sizewell area. In order to inform coastal managerial bodies of appropriate adaptation strategies, it is vital that there is an adequate understanding of past coastal change, current coastal processes and the capacity of a given area of the coast to respond to changes in forcing factors (Pye and Blott, 2006; Spencer and Brooks, 2012). The severity of current forcing factors can be illustrated by the extensive damage and disruption along the coast caused by the major storm surge in December 2013, although the nuclear site was not impacted (Spencer et al., 2015). It is also important to note here that stakeholders have been modifying the Suffolk coastline and addressing climate variability for hundreds of years (Rowland, 1978) regardless of the attribution to climate change.

According to the 2009 Environment Agency's Shoreline Management Plan 7 (SMP), Lowestoft to Felixstowe Landguard Point, the area within the "Sizewell nuclear neighbourhood" (Policy Development Zone 4), which is currently vulnerable to flood risk, is approximately 880 ha and includes 34 properties (Fig. 2). The area vulnerable to erosion is approximately 75 ha (2015 predication - no defences). Vulnerable areas and infrastructure within the SMP area include an RSPB nature reserve, adjacent to the proposed new built site, a gravitational sluice used to drain the nature reserve, significant amounts of ecologically protected marshes, the Sizewell power stations, Sizewell cliffs and a caravan park (Fig. 2).
Adaptation efforts in the nuclear neighbourhood occur on a variety of scales: from international and national initiatives implemented by central government for example, the SMP, to regional and/or local adaptation projects initiated by community groups and local government. There are also a wide range of stakeholders present in the Sizewell nuclear neighbourhood, representing a variety of sectors, including environmental organisations, conservation and energy companies.

\section{Methodology}

In order to determine the extent to which the theoretically established frameworks SL, VL and DC are applicable to real-world practice, an online survey was conducted. Coastal adaptation projects in the study area that have a significant climate change dimension were identified. Following Tompkins et al. (2010), the search engine Google was utilised to conduct a semi-exhaustive internet survey. Combinations of key words were used in order to identify climate change adaptation schemes which were planned or have been implemented in the nuclear neighbourhood. Key words for the search included "adapt", "adaptation", "project", "initiative", "management", "climate change", "Suffolk", "Sizewell", "flooding", "erosion", "adjustment", "hazard", "storm", "adaptive capacity", "vulnerability", "vulnerable", "environment" and "behaviour". An inventory of the 14 adaptation projects was compiled and 


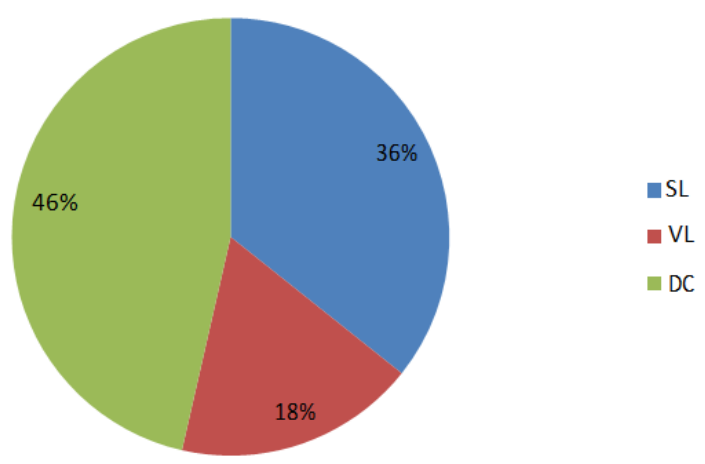

Figure 3. Frameworks adopted by adaptation projects on the Suffolk coast. Relative frequency of adaptation frameworks utilised in adaptation projects in the nuclear neighbourhood.

each project was categorised by hallmark into a theoretical framework (SL/VL/DC) (Table A2).

The organisation, project title, scale of project and organisations affiliated with the project were recorded. Relevant documentation was analysed and a brief description of each project provided. The nature of the implementation was categorised into risk assessment, advice, policy and infrastructure (Table A2). Although the inventory was not arranged by sector, adaptation projects fell predominantly into the water (flooding), biodiversity, construction, business and transport sectors. The scale of each adaptation project was also recorded. Information on the scale and the nature of adaptation frameworks gives an indication to what degree adaptation projects in the nuclear neighbourhood are initiated from a centralised or local administration (Tompkins et al., 2008).

The criterion (Table A1) was used to analyse projects by hallmark. Each project identified on the Suffolk coastline was categorised by the six characteristic hallmarks: (1) use of climate model information; (2) analysis of metrics/units; (3) socio-economic knowledge; (4) stakeholder engagement; (5) adaptation of implementation mechanisms; (6) tier of adaptation implementation. This allowed a comparison of their similarity to the three theoretical adaptation frameworks. As the categorisation of each hallmark was independent, a given adaptation project may feature more than one framework characteristic. In this case adaptation projects are categorised as utilising a hybrid framework.

\section{Results}

The study uncovered 14 individual adaptation projects planned or operational in the nuclear neighbourhood (Table A2). The results first outline the organisations involved in adaptation projects in the nuclear neighbourhood. The framework approaches utilised by organisations in the nuclear neighbourhood are then analysed before exploring the nature of their application.
Table 1. Percentage usage of climate change adaptation frameworks in the nuclear neighbourhood.

\begin{tabular}{lccr}
\hline & VL & DC & SL \\
\hline VL & $14 \%$ & $21 \%$ & $0 \%$ \\
DC & & $21 \%$ & $36 \%$ \\
SL & & & $8 \%$ \\
\hline
\end{tabular}

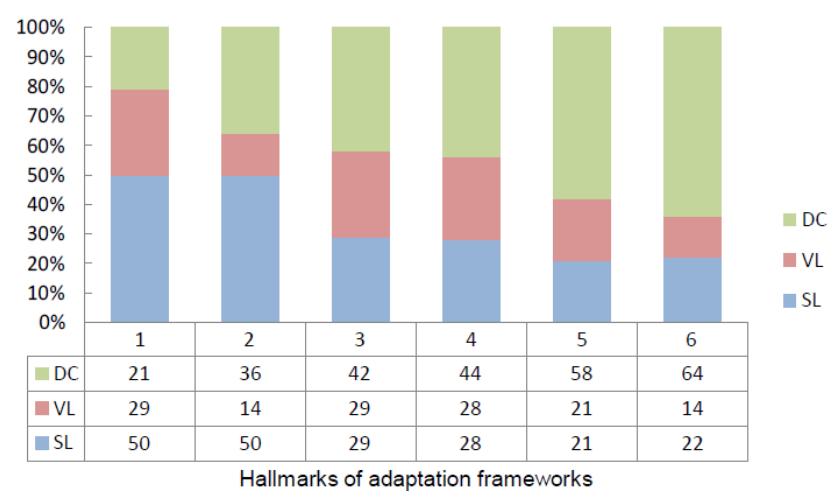

Figure 4. Percentage occurrence of frameworks adopted in adaptation projects in the nuclear neighbourhood categorised by hallmarks 1 to 6 (Table A1).

\subsection{Participants in climate change adaptation projects in the nuclear neighbourhood}

The study confirmed that adaptation is typically a multiagency endeavour. In total, 14 individual organisations were involved in the projects: Alde and Ore Association (AOA), Area of Outstanding Natural Beauty (AONB), Deben Estuary Partnership (DEP), East of England Climate Change Adaptation Partnership (EOECAP), EDF Energy (EDF), Environment Agency (EA), Farmers' Union (NFU), National Trust (NT), Natural England (NE), Royal Society for the Protection of Birds (RSPB), Suffolk Coastal District Council (SCDC), Suffolk County Council (SCC), Suffolk Internal Drainage Board (ESIDB) and Waveney District Council (WDC). The Suffolk coastline demonstrates that a broad cross section of society is involved in climate change adaptation projects. A configuration of statutory, non-statutory and community-based organisations from varying sectors were engaged in adaptation projects surveyed in the study area.

\subsection{Frameworks utilised in climate change adaptation projects in the nuclear neighbourhood}

The inventory (Table A2) suggests that the dominant framework used when implementing climate change adaptation projects is the DC approach (Fig. 3). However, both the SL and VL frameworks combined account for $>50 \%$ of the framework allocation. On further examination the study demonstrates that individual adaptation projects in the nu- 


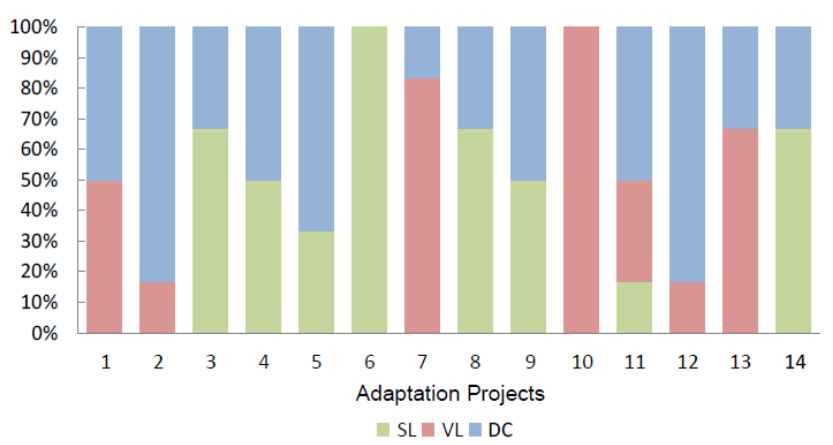

Figure 5. Adaptation frameworks utilised by each adaptation project (see Table A2).

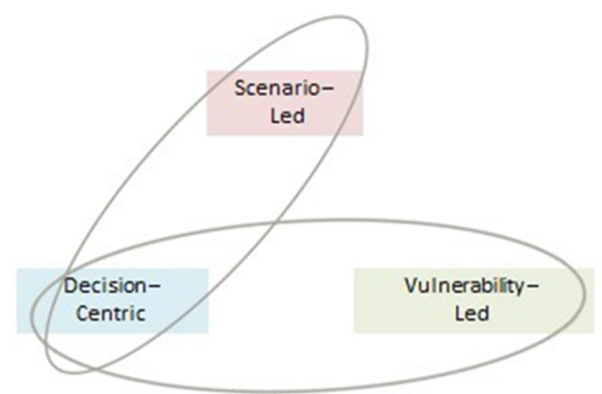

Figure 6. Hybrid of frameworks utilised in climate change adaptation projects in the neighbourhood of Sizewell nuclear power station, Suffolk, UK.

clear neighbourhood utilise more than one framework approach (Fig. 4). Table 1 demonstrates that hallmarks from the DC framework are encompassed within an adaptation project $80.3 \%$ of the time.

Combined VL and SL are the dominant framework approach in all but two hallmarks: (5) implementation and (6) scale of implementation where the DC framework approach is adopted 58 and $64 \%$, respectively. This would indicate that weaknesses associated with SL and VL frameworks (Sects. 2.1 and 2.3) may prevent the nature of the deployment of adaptation projects; uncertainty and resource demand may be too great.

It is important to recognise that although each adaptation project can be categorised, by majority, into one of the three established frameworks, each adaptation project exhibits hallmarks from more than one framework (Fig. 5). As a result it is proposed that in practice, it may not be appropriate to determine the efficacy of each adaptation framework individually as it appears that a hybrid approach is being adopted in the Suffolk coastal zone, UK (Fig. 6).

The adaptation inventory of the neighbourhood surrounding Sizewell nuclear power station indicates that in practice, a hybrid of framework hallmarks are encompassed in any one climate change adaptation project (Figs. 5 and 6). Adaptation projects exhibit either hallmarks from SL and DC frame-

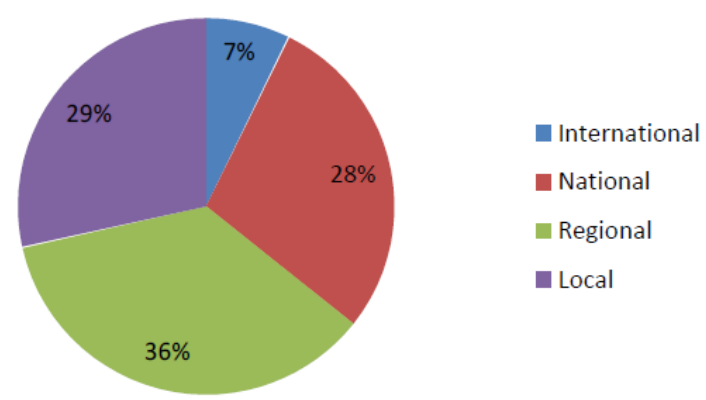

Figure 7. Relative regional scales of adaptation schemes surveyed in the nuclear neighbourhood.

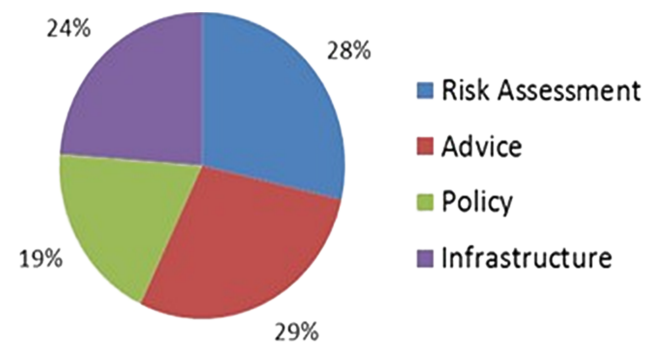

Figure 8. Outcomes of adaptation projects deployed in the Suffolk coastal zone.

works or VL and DC frameworks. Only on one occasion did the inventory record a least one of the hallmarks from all three frameworks. In general it appears that SL and VL hallmarks are not found within the same adaptation plan (Fig. 6).

\subsection{Application of climate change adaptation projects in the nuclear neighbourhood}

When analysing the spatial scales of adaptation schemes deployed in the nuclear neighbourhood, it is evident that the majority of adaptation projects operate on regional or local (site-specific) scales (Fig. 7). The scale of the projects is ascertained by the operational level of the organisation leading the project; for example EDF operates internationally, whereas the Alde and Ore Association only operates locally.

Upon reviewing the implementation pathways of adaptation projects, $57 \%$ of projects resulted in risk assessment and advice (Fig. 8). This suggests that there is insufficient certainty and confidence to implement practical on-the-ground adaptation initiatives as amendments to policies and infrastructure developments appear to be limited.

\section{Discussion}

Climate change adaptation on the Suffolk coastline provides some evidence that elements of theoretical adaptation frameworks are utilised in real-world situations. However, there appears to be discrepancies between defined frameworks within the literature and the nature of real-world adapta- 
tion initiatives in coastal Suffolk. Adaptation efforts on the Suffolk coast rarely utilise one framework in isolation; hallmarks of two frameworks are displayed in a single adaptation project (Fig. 6). This indicates that the practical application of theoretical climate change adaptation frameworks, on the Suffolk coast, appears to be more complex than that outlined in the literature. There are several factors that could explain this hybrid approach.

\subsection{Framework limitation compensation}

As discussed (Sect. 2), each theoretical adaptation framework (SL, VL and DC) has inherent strengths and weaknesses. When applied to real-world situations, the limitations of the frameworks must be overcome in order to make informed and robust adaptation decisions. In line with the literature, it appears on the Suffolk coast that SL and VL framework approaches are supported in part to some degree by aspects of the DC framework (Fig. 5). It appears that SL and VL frameworks are mutually exclusive and do not appear within the same initiative simultaneously; instead two hybrid approaches (Fig. 6) are commonly adopted (i.e. SL/DC and VL/DC). Decision makers may implement a hybrid approach to compensate for weaknesses in aspects of individual frameworks.

Uncertainty is a factor that hampers adaptation decision making. It affects variables of both the inputs and outputs of adaptation projects. There is an extensive and established literature outlining the various facets of uncertainty affecting climate change adaptation both in physical and social disciplines. Uncertainty is regarded such a significant barrier to adaptation decision making that the effectiveness of an adaptation strategy is often measured by the robustness to uncertainty and the flexibility or ability to alter should circumstance change (Adger et al., 2009; Hallegatte, 2009).

Technical uncertainty affects the SL framework as it relies largely on the ability of climate models to predict future changes. Uncertainty stems from insufficient resolution and inability for climate models to accurately simulate the complete set of processes and phenomena centrally important for the attribution of past climate changes and therefore projection of future climate (Bader et al., 2008). Uncertainty is also present when considering effects of future forcing. In addition, conventional SL framework approaches do not adequately incorporate climate change mitigation and adaptation (Moss et al., 2010). Although technical advancements are ongoing (Hackney et al., 2013), uncertainty originating from climate model outputs amplifies as the decision making pathway progresses. Ultimately, the cascade of uncertainty confounds "predict-then-act" strategies (Wilby and Dessai, 2010). At the decision making interface the physical outputs from a SL framework face a complex array of social variables, on which decisions made will impact. Deploying concrete adaptation actions solely from a SL frame- work approach is therefore not a viable option as community response cannot be generalised or predicted.

The results from the Suffolk coast illustrate the limitations associated with employing a SL framework. There is a correlation between the framework adopted and the resulting adaptation actions taken. Projects employing a predominantly SL framework approach tend to result in advice notes and risk assessment reports rather than on-the-ground adaptation actions. On the other hand, VL approaches to adaptation tend to lead to the empowerment of local groups to take action such as the Alde and Ore Futures Projects and the Deben Estuary Partnership (Table A2).

In order to translate advice and risk assessments produced by SL frameworks into action, whilst addressing uncertainty, stringent cost-benefit analyses are necessary. The VL framework advocates collating variables that contribute to costbenefit analysis; however, this may require considerable resources. Some uncertainties can be quantified, but many simply cannot due to limitations in knowledge, leaving some level of irreducible ignorance in our understandings of future climate change adaptation (Dessai and Hulme, 2004).

It is recognised that society can and must make adaptation decisions in the absence of accurate and precise climate change predictions (Dessai et al., 2009). The DC framework may be pitched as a constructive way for overcoming the weaknesses and uncertainties of SL and VL adaptation frameworks because it provides a platform for flexible and robust climate change adaptation. Utilising an adaptation framework that incorporates possible climate change pathways simultaneously with socio-economic impacts and feedback will improve the analysis of complex issues, such as the costs, benefits and risks of different policy choices, climate scenarios and socio-economic futures (Moss et al., 2010). Adaptation projects on the Suffolk coast exhibit this via utilising a hybrid of adaptation frameworks (Fig. 5).

\subsection{Reactive vs. proactive adaptation to climate change}

In the presence of climate change uncertainty it is impossible to denote whether climate change adaptation projects are addressing the threats posed by anthropogenic climate change or responding to climate shocks and coastal change deriving from climate variability. The Suffolk coast is one of the most rapidly eroding coastlines in Europe; coastal communities have experienced climatic extremes following both historic and recent events such as the winter storms of 1953 and 2013/2014. The number of adaptation initiatives designed and implemented by local authorities and community groups (Figure 7) demonstrate that there is an appreciation of the severity of risk and a desire to implement adaptation responses.

Through these personal experiences, local groups in the nuclear neighbourhood recognise the threat that extremes in climate variability pose to coastal assets; they are taking responsibility to implement adaptation projects for ex- 
ample, by enabling development outside of the footprint of their village to generate capital for coastal defence projects (East Lane Enabling Developments; Table A2). In the absence of certainty regarding the impacts of anthropogenic climate change, adaptation projects are currently addressing impacts of coastal change. Adaptation projects are therefore reactive to both shocks induced from climate variability and coastal change but proactive in response to anthropogenic climate change, which may help lessen the impacts of possible impacts.

The UK environment sector has experienced significant cuts in government resources following the economic recession of 2008. Decreased centralised funding has prompted an increase in local community response to coastal change, for example, the Deben Estuary Partnership. Community-led adaptation generally adopts a VL framework promoting community engagement in decision making. Although the participation and empowerment of the local community is widely regarded a positive factor for climate change adaptation (Few et al., 2007), in some cases, the employment of the VL approach on the Suffolk coast has led to actions being implemented that are not in line with the recommendations of management guidance documents such as the SMP. For example, cliff-top land owners have installed hard defences at the base of cliff faces in an effort to mitigate the effects of erosion. Such actions may be deemed acceptable as the SMP is not a statutory document.

Although there is a widespread awareness that the potential impacts of climate change in coastal zones may be significant, the application and success of adaptation actions are plagued with uncertainties deriving from both geomorphological and socio-economic feedbacks. Due to this, the mechanisms by which adaptation is planned and implemented require more assessment and consideration (Nicholls and Cazenave, 2010). The nuclear neighbourhood on the Suffolk coastline illustrates this assertion, although exhibiting both reactive and proactive adaptation project framework analysis, enabled via the criterion, indicates that approaches taken when implementing adaptation projects are varied, not standardised or without limitations (Sect. 2). Varying use of different framework approaches, by numerous stakeholder groups in the nuclear neighbourhood, may exacerbate difference of priorities on actions taken when implementing adaptation initiatives.

\section{Conclusions}

This paper has set out a criterion for classifying adaptation plans into three key frameworks gleaned from the literature. It then tested the validity of the criterion by analysing adaptation framework approaches in coastal Suffolk. It found that there is a disparity between the theoretical classification of climate change adaptation frameworks (SL, VL and DC) and practical adaptation initiatives. Coastal adaptation to climate change is a fluid process, with multiple factors that cannot be classified neatly by a single framework approach: hence, hybrid approaches are most common (Fig. 6). On the Suffolk coastline the most frequent hybrid frameworks utilised are SL/DC and VL/DC combinations (Fig. 6).

Adaptation on the Suffolk coast has highlighted the limitations of individual adaptation frameworks in practice and demonstrated that it is impractical to use one framework in isolation. Although adaptation projects on the Suffolk coast adopt a hybrid of the theoretical frameworks, the composition of each hybrid approach is different. This indicates that, to date, there is no standardised "best practice" framework approach that suits all stakeholders. Disparities between stakeholder adaptation approaches may act as a barrier to the aspirations of current management strategies such as the SMP; managing the coastal zone in a way which reflects natural systems rather than authoritative or organisational boundaries may be impossible if decision makers approach the task from a variety of vantage points. These findings echo the concerns expressed by Burton et al. (2004) that practical guidance on implementing adaptation has not kept pace with the awareness of its need.

In order for decision makers to implement effective climate change adaptation projects, it would appear that a hybrid of frameworks has important advantages (Fig. 5). This paper asserts that the hybrid approach occurs in order to compensate for known weaknesses in SL and VL frameworks revolving around uncertainty and resource strain respectively.

It is important to note that in coastal Suffolk, climate change adaptation is developing against a backdrop of existing initiatives set up in response to a long history of erosion and extreme events such as the winter storms of 1953 and 2013/14. In the presence of uncertainty, a mixture of proactive and reactive adaptation initiatives are evident: reactive in response to extreme events exacerbating coastal change as well as proactive in anticipation of anthropogenic climate change impacts. The nature of the response may also affect the adaptation framework adopted along with the resource availability of stakeholders implementing adaptation projects and how effectively stakeholders collaborate on projects.

Similar matrices to the criterion presented in this paper (Table A1) have been used to explore climate risk assessment in the water sector, assessing methodological strengths and weaknesses of SL and VL approaches linked to climate model outputs (e.g. Ekström et al., 2013). However there is further scope for refinement as the categorisation of each framework requires identification of specific hallmarks evident as part of the adaptation scheme. In addition, it is recognised that the portfolio of adaptation projects represents a snapshot in time; an adaptation scheme may develop in such a way that the initial classification of hallmarks may no longer be appropriate. It is also important to recognise that the study only assessed one medium: formal documentation of a given adaptation project. Surveying additional mediums such as blogs and websites might enable a more in-depth un- 
derstanding of the frameworks adopted by stakeholders when implementing climate change adaptation initiatives. A longitudinal study into adaptation evolution would further aid the identification of critical indicators that govern the "successes" of climate change adaptation projects. This survey only harnesses a certain type of presence in the adaptation realm; there are many informal initiatives being undertaken that the methodology of this study did not encompass. A longitudinal study would enable the exploration of these informal stakeholder interactions and adaptation initiatives.
The criterion presented in this study provides a platform for further analysis of climate change adaptation frameworks adopted in other coastal locations. It highlights that a fluid approach to adaptation needs to be taken. More extensive research must be conducted to further establish frameworks of best practice to aid stakeholders and provide sufficient guidance when implementing climate change adaptation projects. Further analysis is needed to better understand the motivations and limitations of stakeholders when adopting frameworks to implement adaptation initiatives on the coast. A comprehensive understanding of the factors that affect stakeholders utilising certain adaptation frameworks will enable recommendations to be made as to in what way organisations may collaborate more effectively to enable adaptation to be implemented "successfully" at a neighbourhood scale surrounding long-lived static infrastructure. These conclusions are probably transferable to proactive long-term planning in other issues than adaptation to climate change. 


\section{Appendix A}

Table A1. Criteria defining the hallmarks of each adaptation framework.

\begin{tabular}{|c|c|c|c|}
\hline Hallmarks & Scenario-led & Vulnerability-led & Decision-centric \\
\hline $\begin{array}{l}\text { 1. Use of } \\
\text { climate } \\
\text { model } \\
\text { information }\end{array}$ & Widespread use of regional downscaling & Focus on natural climate variability & $\begin{array}{l}\text { Climate models used to relate changes in physical boundary } \\
\text { conditions to coping thresholds of stakeholders } \\
\text { Processing of climate model output not done } \\
\text { Climate model information often collated into representative } \\
\text { climate futures (RCFs) which are then used to assess the sensitivity } \\
\text { of a potentially vulnerable community }\end{array}$ \\
\hline $\begin{array}{l}\text { 2. Analysis of } \\
\text { metrics/ } \\
\text { units }\end{array}$ & $\begin{array}{l}\text { Use of predicted impact metrics e.g. } \\
\text { physical and biophysical parameters such } \\
\text { as crop yield, precipitation rate } \\
\text { Historical data sets often used as a } \\
\text { baseline to measure change }\end{array}$ & $\begin{array}{l}\text { Identification of factors which govern the ability to cope } \\
\text { successfully with climate-related threats } \\
\text { Identification of socio-economic implications that govern } \\
\text { resilience thresholds }\end{array}$ & $\begin{array}{l}\text { Encompasses metrics used in both SL and VL frameworks } \\
\text { Sensitivity or stress-testing utilised and performance metrics used to } \\
\text { monitor the efficacy adaptation project } \\
\text { Determines the thresholds in which substantial investments or } \\
\text { policy shifts would be required }\end{array}$ \\
\hline $\begin{array}{l}\text { 3. Socio- } \\
\text { economic } \\
\text { knowledge }\end{array}$ & $\begin{array}{l}\text { Does not assess socio-economic factors } \\
\text { affecting coping capacities }\end{array}$ & $\begin{array}{l}\text { Develops an understanding of the dynamic factors that may } \\
\text { affect coping capacity of a community }\end{array}$ & $\begin{array}{l}\text { Prioritises identification of coping capacity of primary vulnerabilities } \\
\text { of the potentially affected community }\end{array}$ \\
\hline $\begin{array}{l}\text { 4. Stakeholder } \\
\text { engagement }\end{array}$ & $\begin{array}{l}\text { Typically occurs at the final stages of the } \\
\text { process as risk communication }\end{array}$ & $\begin{array}{l}\text { Extensive consultation throughout } \\
\text { Community involvement to actively manage risk and } \\
\text { implement adaptation } \\
\text { Project instigated and managed by the affected community }\end{array}$ & $\begin{array}{l}\text { Extensive consultation throughout } \\
\text { Identification of coping capacity by stakeholders and experts from } \\
\text { the beginning of the adaptation process } \\
\text { Authoritative organisations and bodies most commonly engaged }\end{array}$ \\
\hline $\begin{array}{l}\text { 5. Adaptation } \\
\text { implementation } \\
\text { mechanisms }\end{array}$ & $\begin{array}{l}\text { Advising the decision maker of potential } \\
\text { changes to physical boundary conditions }\end{array}$ & Improving coping strategies of stakeholders & $\begin{array}{l}\text { Adaptation occurs via stress-testing options and is constantly } \\
\text { reassessed and updated } \\
\text { Systematic monitoring and review of risks. }\end{array}$ \\
\hline $\begin{array}{l}\text { 6. Tier of } \\
\text { adaptation } \\
\text { implementation }\end{array}$ & $\begin{array}{l}\text { Most commonly national or } \\
\text { international scale } \\
\text { Implementation from a centralised position } \\
\text { within society such as national government }\end{array}$ & $\begin{array}{l}\text { Most commonly local governance level } \\
\text { Adaptation projects can be informal initiatives that respond } \\
\text { to (perceived) risk by the local community }\end{array}$ & $\begin{array}{l}\text { Mostly frequently on a regional scale } \\
\text { Most often focused on individual projects or specific areas. } \\
\text { Adaptation schemes are cross-sectorial } \\
\text { Immediate updates to adaptation strategy should conditions } \\
\text { governing risk change }\end{array}$ \\
\hline
\end{tabular}


Table A2. The dominant framework takes a single framework if five hallmarks are in the same framework and hybrid frameworks where at least two hallmarks are in the same framework.

\begin{tabular}{|c|c|c|c|c|c|c|c|c|c|c|}
\hline \multirow[t]{2}{*}{$\begin{array}{l}\text { Document or } \\
\text { project title }\end{array}$} & \multirow[t]{2}{*}{$\begin{array}{l}\text { Organisations } \\
\text { affiliated }\end{array}$} & \multicolumn{6}{|c|}{$\begin{array}{l}\text { Classification of adaptation projects } \\
\text { by framework }\end{array}$} & \multirow[t]{2}{*}{ Stage } & \multirow[t]{2}{*}{ Scale } & \multirow{2}{*}{$\begin{array}{l}\text { Dominant } \\
\text { framework } \\
\text { displayed }\end{array}$} \\
\hline & & 1 & 2 & 3 & 4 & 5 & 6 & & & \\
\hline Futurescapes & RSPB & VL & $\mathrm{DC}$ & $\mathrm{VL}$ & VL & $\mathrm{DC}$ & DC & $\begin{array}{l}\text { Actions } \\
\text { (ongoing) }\end{array}$ & $\begin{array}{l}\text { National } \\
\text { initiative, } \\
\text { regional focus }\end{array}$ & VL/DC \\
\hline $\begin{array}{l}\text { The Suffolk } \\
\text { Shoreline } \\
\text { Management } \\
\text { Plan } 7 \\
\text { (SMP 7) }\end{array}$ & $\begin{array}{l}\text { EA, SCDC, } \\
\text { WDC }\end{array}$ & DC & $\mathrm{DC}$ & VL & DC & DC & DC & $\begin{array}{l}\text { Actions } \\
\text { monitoring } \\
\text { (ongoing) }\end{array}$ & $\begin{array}{l}\text { National } \\
\text { initiative, } \\
\text { regional focus }\end{array}$ & $\mathrm{DC}$ \\
\hline $\begin{array}{l}\text { SMP } 7 \text { (MIN 12-13) } \\
\text { Minsmere Flood } \\
\text { Risk Management } \\
\text { Scheme }\end{array}$ & EA & SL & SL & DC & DC & SL & SL & $\begin{array}{l}\text { Actions } \\
\text { monitoring } \\
\text { (ongoing) }\end{array}$ & $\begin{array}{l}\text { National plan, } \\
\text { regional/local } \\
\text { focus }\end{array}$ & SL/DC \\
\hline $\begin{array}{l}\text { Minsmere Sea- } \\
\text { defence Project }\end{array}$ & RSPB, EA & SL & SL & DC & SL & DC & DC & $\begin{array}{l}\text { Actions } \\
\text { (completed } \\
\text { 2012) }\end{array}$ & Regional & SL/DC \\
\hline $\begin{array}{l}\text { Future Landscapes } \\
\text { - climate change } \\
\text { impacts and } \\
\text { adaptation in the } \\
\text { Suffolk Coast and } \\
\text { Heaths AONB }\end{array}$ & $\begin{array}{l}\text { The East of } \\
\text { England } \\
\text { Climate Change } \\
\text { Adaptation } \\
\text { Partnership } \\
\text { SCC, NE, } \\
\text { SCLSP, NFU }\end{array}$ & SL & SL & DC & DC & DC & DC & $\begin{array}{l}\text { Actions } \\
\text { (completed } \\
\text { 2012) }\end{array}$ & Regional & $\mathrm{DC}$ \\
\hline $\begin{array}{l}\text { National Flood and } \\
\text { Coastal Erosion } \\
\text { Risk Management } \\
\text { Strategy }\end{array}$ & EA & SL & SL & SL & SL & SL & SL & $\begin{array}{l}\text { Actions } \\
\text { (ongoing) }\end{array}$ & National & SL \\
\hline $\begin{array}{l}\text { East Suffolk } \\
\text { Internal Drainage } \\
\text { Board }\end{array}$ & ESIDB, EA, NE & $\mathrm{VL}$ & $\mathrm{VL}$ & DC & $\mathrm{VL}$ & $\mathrm{VL}$ & $\mathrm{VL}$ & $\begin{array}{l}\text { Actions } \\
\text { (ongoing) }\end{array}$ & Regional & $\mathrm{VL}$ \\
\hline $\begin{array}{l}\text { EU Stress Test - } \\
\text { Sizewell B }\end{array}$ & EDF & SL & SL & SL & SL & $\mathrm{DC}$ & DC & Actions & International & SL/DC \\
\hline $\begin{array}{l}\text { Report on } \\
\text { Adaptation Under } \\
\text { the Climate } \\
\text { Change Act } 2008\end{array}$ & $\mathrm{EDF}$ & SL & SL & SL & DC & $\mathrm{DC}$ & DC & $\begin{array}{l}\text { Process } \\
\text { (ongoing) }\end{array}$ & International & SL/DC \\
\hline $\begin{array}{l}\text { Alde and Ore } \\
\text { Estuary Futures }\end{array}$ & $\begin{array}{l}\text { EA, NE, } \\
\text { AOA }\end{array}$ & $\mathrm{VL}$ & VL & $\mathrm{VL}$ & $\mathrm{VL}$ & $\mathrm{VL}$ & $\mathrm{VL}$ & Actions & Local & VL \\
\hline $\begin{array}{l}\text { Deben Estuary } \\
\text { Plan }\end{array}$ & $\begin{array}{l}\text { DEP, EA, } \\
\text { NE, SCDC }\end{array}$ & SL & $\mathrm{DC}$ & VL & VL & DC & DC & Actions & Local & VL/DC \\
\hline $\begin{array}{l}\text { East Lane } \\
\text { Enabling } \\
\text { Developments }\end{array}$ & $\begin{array}{l}\text { AONB, DEP, } \\
\text { NT, SCDC, } \\
\text { EA, NE }\end{array}$ & $\mathrm{DC}$ & DC & $\mathrm{DC}$ & VL & $\mathrm{DC}$ & $\mathrm{DC}$ & Actions & Local & DC \\
\hline Touching the Tide & AONB & VL & VL & VL & DC & VL & $\mathrm{DC}$ & Actions & Local & $\mathrm{VL} / \mathrm{DC}$ \\
\hline $\begin{array}{l}\text { Sluice } \\
\text { maintenance - } \\
\text { Minsmere }\end{array}$ & EA & $\mathrm{DC}$ & SL & SL & SL & SL & DC & Actions & Local & SL/DC \\
\hline
\end{tabular}


Acknowledgements. EPSRC is acknowledged for providing the funding for the research though the ARCC programme and the ARCoES project: EP/I035390/1.

Edited by: P. Ciavola

Reviewed by: five anonymous referees

\section{References}

Adger, N. W., Arnell, N. W., and Tompkins, E. L.: Successful adaptation to climate change across scales, Global Environ. Change, 15, 77-86, 2005.

Adger, N. W., Dessai, S., Goulden, M., Hulme, M., Lorenzoni, I., Nelson, Wolf, L. O. N. J., and Wreford, A.: Are there social limits to adaptation to climate change?, Climate Change, 93, 335-354, 2009.

Bader, D., Covey, C., Gutowski, W., Held, I., Kunkel, K., Miller, R., Tokmakian, R., and Zhang, M.: Climate Models: An Assessment of Strengths and Limitations, US Department of Energy Publications, 8, 1-6, 2008.

Brooks, N., Adger, W. N., and Kelly, P. M.: The determinants of vulnerability and adaptive capacity at the national level and the implications for adaption, Global Environ. Change, 15, 151-163, 2005.

Brown, C. and Wilby, R. L.: An alternate approach to assessing climate risks, Eos Trans. Am. Geophys. Union, 93, 401-402, 2012.

Brown, C., Werick, W., Leger, W. and Fay, D.: A decision - analytic approach to managing climate risks: Application to the upper Great Lakes, J. Am. Water Resourc. Assoc., 47, 524-534, 2012.

Burton, I., Malone, E., and Huq, S.:Adaptation Policy Frameworks for Climate Change: Developing Strategies, Policies and Measures, Cambridge University Press, New York, 2004.

Craig, R. K.: 'Stationarity is Dead' - Long Live Transformation: Five Principles for Climate Change Adaptation Law, Harvard Environ. Law Rev., 34, 9-75, 2010.

Dang, H. H., Michaelowa, A., and Tuan, D. D.: Synergy of adaptation and mitigation strategies in the context of sustainable development: the case of Vietnam, Climate Policy, 3, 81-96, 2003.

DEFRA - Department for Environment, food and Rural Affairs: North Norfolk Coastal Change Pathfinder, available at: http://www.defra.gov.uk/environment/flooding/ coastal-change-pathfinders/east/, last access: 10 December 2012.

Delgado, J. A., Groffman, P. M., Nearing, M. A., Goddard, T., Reicosky, D., and Lal, R.: Conservation practices to mitigate and adapt to climate change, J. Soil Water Conserv., 66, 118-129, 2011.

Dessaia, S., Lua, X., and Risbey, J. S.: On the role of climate scenarios for adaptation planning, Global Environ. Change, 15, 87-97, 2004.

Dessai, S. and Hulme, M.: Does climate adaptation policy need probabilities?, Climate Policy, 4, 107-128, 2004.

Dessai, S., Hulme, M., Lempert, R., and Pielke Jr., R.: Climate prediction: a limit to adaptation, in: Adapting to Climate Change: Thresholds, Values, Governance, edited by: Adger, W. N., Lorenzoni, I., and O'Brien, K. L., Cambridge University Press, 64-78, 2009.
Dickson, M. E., Walkden, M., and Hall, J.: Systemic impacts of climate change on an eroding coastal region over the twenty-first century, Climatic Change, 84, 141-166, 2007.

EDF Energy: Sizewell C Stage 1 Consultation, Environmental Report, available at: http://sizewell.edfenergyconsultation.info/ wp-content/uploads/SzC-Stage-1-Environmental-Report.pdf (last access: 9 December 2014), 2012.

Eisenack, K. and Stecker, R.: A framework for analysing climate change adaptations, Mitig. Adapt. Strat. Global Change, 12, $243-$ 260, 2012.

Ekström, M., Kuruppu, N., Wilby, R. L., Fowler, H. J., Chiew, F. H. S., Dessai, S., and Young, W. J.: Examination of climate risk using a modified uncertainty matrix framework- Applications in the water sector, Global Environ. Change, 23, 115-129, 2013.

Environment Agency: Shoreline Management Plan 7, Felixstowe to Lowestoft, available at: https://www.gov.uk/ government/publications/shoreline-management-plans-smps/ shoreline-management-plans-smps (last access: 28 April 2015), 2009.

Fankhauser, S., Smith, J. B., and Tol, R. S. J.: Weathering climate change: some simple rules to guide adaptation decisions, Ecol. Econ., 30, 67-78, 1999.

Few, R., Brown, K., and Tompkins, E. L.: Public participation and climate change adaptation: avoiding the illusion of inclusion, Climate Policy, 7, 46-59, 2007.

French, P.: Coastal Defences: Processes, problems and solutions, Routledge, London, 2001.

Füssel, H. M.: Vulnerability: A generally applicable conceptual framework for climate change research, Global Environ. Change, 2, 155-167, 2007.

Hackney, C., Darby, S. E., and Leyland, J.: Modelling the response of soft cliffs to climate change: A statistical, process-response model using accumulated excess energy, Geomorphology, 187, 108-121, 2013.

Hallegatte, S.: Strategies to adapt to an uncertain climate change, Global Environ. Change, 19, 204-247, 2009.

Her Majesty's Government: Climate Change Act, http://www. legislation.gov.uk/ukpga/2008/27/pdfs/ukpga_20080027_en.pdf (last access: 15 December 2014), 2008.

IPCC: Summary for Policymakers, in: Climate Change 2013: The Physical Science Basis, Contribution of Working Group I to the Fifth Assessment Report of the Intergovernmental Panel on Climate Change, edited by: Stocker, T. F., Qin, D., Plattner, G. K., Tignor, M., Allen, S. K., Boschung, J., Nauels, A., Xia, Y., Bex, V., and Midgley, P. M., Cambridge University Press, Cambridge, UK and New York, NY, USA, 1-30, doi:10.1017/CBO9781107415324.004, 2013.

Kleina, R. J. T., Schipperc, L. F., and Dessai, S.: Integrating mitigation and adaptation into climate and development policy: three research questions, Nature, 8, 579-588, 2005.

Measham, T. G., Preston, B. L., Smith, T. F., Brooke, C., Gorddard, R., Withycombe, G., and Morrison, C.: Adapting to climate change through local municipal planning: barriers and challenges, Mitig. Adapt. Strat. Global Change, 16, 889-909, 2011.

Moser, S. and Eskstrom, J.: A framework to diagnose barriers to climate change adaptation, P. Nalt. Acad. Sci., 107, 22026-22031, 2010.

Moss, R. H., Edmonds, J. A., Hibbard, K. A., Manning, M. R., Rose, S. K., van Vuuren, D. P., Carter, T. R., Emori, S., Kainuma, M., 
Kram, T., Meehl, G. A., Mitchell, J. F. B., Nakicenovic, N., Riahi, K., Smith, S. J., Stouffer, R. J., Thomson, A. M., Weyant, J. P., and Wilbanks, T. J.: The next generation of scenarios for climate change research and assessment, Nature, 463, 747-756, 2010.

Nicholls, R. J. and Cazenave, A.: Sea-Level Rise and Its Impact on Coastal Zones, Science, 18, 1517-1520, 2010.

Nicholls, R. J. Townend, I. H., Bradbury, A. P., Ramsbottom, D., and Day, S. A.: Planning for long-term coastal change: Experiences from England and Wales, Ocean Eng., 71, 3-16, 2013.

O’Neill, B. C., Kriegler, E., Riahi, K., Ebi, K. L., Hallegatte, S., Carter, T. R., Mathur, R., and van Vuuren, D. P.: A new scenario framework for climate change research: the concept of shared socioeconomic pathways, Climatic Change, 122, 387-400, 2014.

Pielke, R. A.: Rethinking to role of climate change adaptation in climate policy, Global Environ. Change, 8, 159-170, 1998.

Pielke Jr., R. A.: The British Climate Change Act: a critical evaluation and proposed alternative approach, Environ. Res. Lett., 4, 1-7, 2009.

Pye, K. and Blott, S. J.: Coastal processes and morphological change in the Dunwich-Sizewell area, Suffolk, UK, J. Coast. Res., 22, 453-473, 2006.

Rowland, P.: Men of Dunwich: The story of a vanished town, Collins, London, UK, 1978.

Semenza, J. C., Ploubidis, G. B., and George, L. A.: Climate change and climate variability: personal motivation for adaptation and mitigation, Environ. Health, 10, 46, 2011.

Sims, R. E. H., Rogner, H. H., and Gregory, K.: Carbon emission and mitigation cost comparisons between fossil fuel, Energy Policy, 1215-1326, 2003.

Smit, B. and Wandel, J.: Adaptation, adaptive capacity and vulnerability, Global Environ. Change, 16, 282-292, 2006.

Solomon, S., Plattner, G., Knutti, R., and Friedlingstien, P.: Irreversible climate change due to carbon dioxide emissions, P. Natl. Acad. Sci., 106, 1704-1709, 2008.

Spencer, T. and Brooks, S. M.: Methodologies for measuring and modelling change in coastal saline lagoons under historic and accelerated sea-level rise, Suffolk coast, eastern England, Hydrobiologia, 693, 99-115, doi:10.1007/s10750-012-1089-x, 2012.
Spencer, T., Brooks, S. M., Evans, B. R., Tempest, J. A., and Möller, I.: Southern North Sea storm surge event of 5 December 2013: Water levels, waves and coastal impacts, Earth Sci. Rev., 146, 120-145, 2015.

Tompkins, E. L., Few, R., and Brown, K.: Scenario-based stakeholder engagement: Incorporating stakeholders preferences into coastal planning for climate change, J. Environ. Manage., 88, 1580-1592, 2008.

Tompkins, E. L., Adger, W. N., Boyd, E., Nicholson-Cole, S., Weatherhead, K., and Arnell, N.: Observed adaptation to climate change: UK evidence of transition to a well-adapted society, Global Environ. Change, 20, 627-635, 2010.

UNEP: The Adaptation Gap Report 2014, United Nations Environnent Programme (UNEP), Nairobi, 2014.

Van Aalst, M. K., Cannon, T., and Burton, I.: Community level adaptation to climate change: The potential role of participatory community risk assessment, Global Environ. Change, 18, 165179, 2008.

Wilby, R. L. and Dessai, S.: Robust adaptation to climate change, Weather, 65, 180-185, 2010.

Wilby, R. L., Dawson, C. W., and Barrow, E. M.: SDSM - a decision support tool for the assessment of regional climate change impacts, Environ. Model. Softw., 17, 145-157, 2002.

Wilby, R. L., Nicholls, R. J., Warren, R., Wheater, H. S., Clarke, D., and Dawson, R. J.: Keeping nuclear and other coastal sites safe from climate change, Proc. Inst. Civil Eng., 164, 129-136, 2011.

Wong, P. P., Losada, I. J., Gattuso, J. P., Hinkel, J., Khattabi, A., McInnes, K. L., Saito, Y., and Sallenger, A.: Coastal systems and low-lying areas, in: Climate Change 2014: Impacts, Adaptation, and Vulnerability, Part A: Global and Sectoral Aspects, Contribution of Working Group II to the Fifth Assessment Report of the Intergovernmental Panel on Climate Change, Cambridge University Press, Cambridge, UK, 361-409, 2014. 